\title{
Age at menopause, extent of coronary artery disease and outcome among postmenopausal women with acute coronary syndromes
}

\author{
Stefano Savonitto ${ }^{\mathrm{a}, *}$, Nuccia Morici ${ }^{\mathrm{b}, \mathrm{c}}$, Nicoletta Franco ${ }^{\mathrm{d}}$, Leonardo Misuraca ${ }^{\mathrm{e}}$, Laura Lenatti ${ }^{\mathrm{a}}$, Luca A. Ferri ${ }^{\mathrm{a}}$, \\ Emilia Lo Jacono ${ }^{\mathrm{f}}$, Chiara Leuzzi ${ }^{\mathrm{f}}$, Elena Corrada ${ }^{\mathrm{g}}$, Tiziana C. Aranzulla ${ }^{\mathrm{h}}$, Angelo Cagnacci ${ }^{\mathrm{i}}$, Delia Colombo ${ }^{\mathrm{j}}$, \\ Carlo La Vecchia ${ }^{\mathrm{c}}$, Francesco Prati ${ }^{\mathrm{k}}$, LADIES ACS Investigators
}

a Ospedale Manzoni, Lecco, Italy

${ }^{\mathrm{b}}$ ASST Grande Ospedale Metropolitano Niguarda Ca' Granda, Milano, Italy

c Dept. of Clinical Sciences and Community Health, Università degli Studi di Milano, Milan, Italy

d Ospedale Infermi, Rimini, Italy

e Ospedale della Misericordia, Grosseto, Italy

${ }^{\mathrm{f}}$ IRCCS Arcispedale S. Maria Nuova, Reggio Emilia, Italy

${ }^{g}$ Humanitas Clinical and Research Center, Rozzano, Italy

h Ospedale Mauriziano, Torino, Italy

${ }^{\text {i }}$ Azienda Sanitaria Universitaria integrata di Udine, Italy

j Clinical Pharmacology, Milan, Italy

k Ospedale San Giovanni Addolorata, CLI Foundation, Rome, Italy

\section{A R T I C L E I N F O}

\section{Article history:}

Received 15 December 2017

Accepted 15 February 2018

Available online 21 February 2018

\section{Keywords:}

Acute coronary syndromes

Sex

Menopause

Coronary angiography

Outcome

\begin{abstract}
A B S T R A C T
Background: Early menopause has been associated with increased cardiovascular mortality, but prospective studies investigating outcomes of postmenopausal women with acute coronary syndromes (ACS) in relation to menopausal age are lacking.

Methods: We analyzed the 1-year outcome of 373 women with acute myocardial infarction enrolled in the Ladies ACS study. All patients underwent coronary angiography, with corelab analysis. Menopause questionnaires were administered during admission. Menopausal age below the median of the study population (50 years) was defined as "early menopause". The composite 1-year outcome included all-cause mortality, recurrent myocardial infarction and stroke.

Results: The mean age at index ACS was 73 years (IQR 65-83) for women with early menopause, and 74 (IQR 65 80) for those with late menopause. Patients with early menopause had more prevalent chronic kidney disease (12.8\% vs 5.9\%, p = 0.03), whereas there were no differences in all other clinical characteristics, extent of coronary disease at angiography (as assessed by Gensini and SYNTAX scores), as well as interventional treatments. Within 1 year, women with late menopause had significantly better outcome as compared with those with early menopause ( $6.5 \%$ vs $15.3 \%, \mathrm{p}=0.007)$. At logistic regression analysis, late menopause was independently associated with better outcome (OR 0.28; 95\% CI 0.12-0.67; $\mathrm{p}=0.004)$. With each year's delay in the menopause the adjusted risk decreased by $12 \%$ (OR 0.88, 0.77-0.99, $\mathrm{p}=0.040$ ).

Conclusion: Despite comparable clinical and angiographic characteristics, women with late menopausal age experience better outcomes after an ACS as compared with those with early menopause.
\end{abstract}

(c) 2018 Elsevier B.V. All rights reserved.

\section{Introduction}

Age at onset of menopause has been shown to be an independent predictor of subsequent cardiovascular events and mortality, with later menopause associated with lower risk [1-6]. Among the potential mechanism of this association are genetic factors that would be

\footnotetext{
* Corresponding author at: Divisione di Cardiologia, Ospedale A. Manzoni, Via dell' Eremo 9, 23900 Lecco, Italy.

E-mail address: s.savonitto@asst-lecco.it (S. Savonitto).
}

responsible of both early reproductive and cardiovascular aging [7], early withdrawal of the vascular protective effect of estrogen $[8,9]$, and a role of the classical cardiovascular risk factors which might be the cause or the consequence of early reproductive failure [10,11]. However, clinical studies investigating the outcomes of postmenopausal women with acute coronary syndrome (ACS) in relation to their age at menopause onset are lacking. In the report of the Ladies ACS study, we showed that age at menopause was not related to the extent of coronary artery disease among postmenopausal women with an ACS [12]. In the present paper, we report the one-year follow-up of that cross- 
sectional study, to address the issue of whether menopausal age is associated with clinical outcome after an ACS.

\section{Methods}

The Ladies ACS study (NCT01997307) is a prospective, multicenter investigation including postmenopausal women and age-matched men with an ACS, stratified in 4 tenyear age groups (55-64, 65-74, 75-85 and $>85$ years) with a sampling ratio of $2: 1$ of women vs men. The details of the study design have been described previously [12]. The focus of the study was angiographic, with a corelab analysis of the angiograms collected at the study sites. However, the investigators of 6 out of 10 participating centers (contributing with $94 \%$ of the study population) volunteered to perform a one-year follow-up to investigate the relation between their clinical and angiographic findings and outcome.

\subsection{Inclusion criteria}

For a patient to be eligible, the following characteristics were required: a) symptoms suggestive of acute myocardial ischemia; b) a typical rise and fall in serum troponin levels [13], and c) electrocardiographic signs of myocardial ischemia. Such characteristics are consistent with the diagnosis of acute myocardial infarction (MI), either with or without ST-segment elevation. All study participants had a clinical indication to coronary angiography as per routine in the participating centers. There were no exclusion criteria, besides a patient's inability to recall reproductive and menopause history, and inability or unwillingness to provide informed consent to the study. Fertile life and menopause history was collected using a specific questionnaire.

\subsection{Data collection}

A web-based case report form (Mediolanum Cardio Research, Milan, Italy) was used to collect data on the personal characteristics (age, body weight, body mass index), the relevant risk factors for coronary disease (hypertension, diabetes mellitus, smoking, dyslipidemia, physical activity), prior clinical history (MI, coronary angioplasty, bypass surgery, and stroke), prognostically relevant variables (such as serum creatinine, chronic kidney disease, blood haemoglobin, left ventricular ejection fraction [LVEF]); characteristics of the acute coronary syndrome (electrocardiographic changes, troponin elevation, Killip class, heart rhythm); angiographic data, coronary revascularization procedures and medications during admission, as well as drugs prescribed at discharge.

Coronary angiograms collected at the participating centers were assessed by an independent core laboratory blinded to patients' age, sex, ST-segment status, and clinical data (European Imaging Laboratory, Rome, Italy). The extent of coronary atherosclerosis at angiography was quantified for each patient using the Gensini score, which includes both angiographically nonsignificant and significant stenoses [14,15]. Diagnostic angiograms were also scored according to the SYNergy between percutaneous coronary intervention with TAXus and cardiac surgery (SYNTAX) score algorithm, a comprehensive anatomic assessment of the coronary disease derived from various preexisting anatomic classifications [16].

Follow-up data were collected by hospital visits or telephone calls. The study was conducted in conformity with the Declaration of Helsinki.

\subsection{Menopause questionnaire}

Women's questionnaire included age at first and last menstrual period, the number of full-term pregnancies, use of oral contraceptives, ongoing and past hormone replacement therapy and whether a hysterectomy and/or oophorectomy had been performed. Age at menarche was defined as the age at the first menstrual period. Age at menopause was defined as age at last menstrual period. Duration of reproductive life span was generated by subtracting age at menarche from age at menopause [17]

\subsection{Endpoints}

The composite study outcome was the 1-year occurrence of all-cause death, recurrent MI (same definition used for the index ACS event) and stroke. As secondary outcome, we considered also re-hospitalization for cardiovascular causes (including severe recurrent ischemia, heart failure, cardiac arrhythmia and systemic embolism).

\subsection{Statistical analysis}

We compared demographics, clinical and angiographic characteristics according to age at menopause, dichotomized by the median of 50 years, which corresponds to the median age at menopause in Europe [18]. Continuous variables were compared using the Student $t$-test for symmetric variables and the Mann-Whitney test by ranks for skewed variables; the results are presented as means and standard deviations (SD) or medians and 25th and 75th percentile, respectively. Discrete variables were compared using the chi squared test and presented as absolute and relative frequencies per category. The exact date of post-discharge events within one-year follow up was not available. Therefore, we fitted a multivariable logistic regression model in order to derive the odds ratio (ORs) and the 95\% confidence interval (CI) of the composite event, adjusted for the following variables: age, LVEF, chronic kidney disease, age at menopause (tested as dichotomous and continuous variable) and SYNTAX score. All analyses were performed using the package STATA/SE 14 (StataCorp LP, College Station, TX).

\section{Results}

\subsection{Baseline characteristics}

The study population consists of 373 patients, and the median age at menopause was 50 years: 203 women had had menopausal age of $\leq 50$ years, and $170 \geq 50$ years. The mean menopausal age was 47 years in women with early menopause, as compared with 53 years in those with late menopause $(p<0.001)$. Menopause was physiological in $79 \%$ of women with early menopause, as compared with $97 \%$ of those with late menopause $(\mathrm{p}<0.001)$. Hormone replacement therapy was assumed by $18 \%$ of women with early menopause as compared with $9.4 \%$ of those with late menopause $(p=0.021)$.

As shown in Table 1, the baseline clinical characteristics, including cardiovascular risk factors, prior medical history and clinical presentation at index ACS events were similar in the two menopausal age groups, except for chronic kidney dysfunction, which was more frequent among women with early menopause. Women with early menopause were taking significantly more ACE-inhibitors. The coronary angiographic findings and revascularization procedures were also similar between menopausal age groups, as were the treatments administered at discharge (Table 2).

\subsection{One-year outcomes}

As reported in Table 3, the rate of the aggregate outcome events was significantly lower in women with late menopause. All individual endpoint components (all-cause mortality, recurrent MI and stroke) were numerically lower in women with late menopause. The adjusted odds ratios for the composite endpoint of death, MI and stroke (OR 0.28; $95 \%$ CI 0.12-0.67; p = 0.004), as well as for the composite endpoint including rehospitalization for cardiovascular causes (OR 0.54; 95\% CI $0.31-0.94, p=0.026$ ) were significantly reduced for women with late menopause. The association of late menopause with better outcome was confirmed at a sensitivity analysis including only women with natural menopause: OR $0.25 ; 95 \%$ C.I. $0.10-0.65, \mathrm{p}=0.004$ for the primary outcome, and OR $0.41 ; 95 \% \mathrm{CI} 0.20-0.84, \mathrm{p}=0.015$ including cardiovascular rehospitalizations. A further sensitivity analysis excluding patients with chronic kidney dysfunction yielded similar results. When age at menopause vas modeled as a continuous variable, each year's delay in the menopause was associated with a $12 \%$ reduction in risk of the composite outcome event (OR 0.88, 0.77-0.99, $\mathrm{p}=0.04$ ).

\section{Discussion}

The LADIES ACS study was aimed at investigating whether age at menopause is associated with the extent of angiographically quantified coronary atherosclerosis in the post-menopausal decades [12]. The answer was clearly that it is not: the extent of coronary disease increased with aging, but didn't show any correlation with menopausal age, both in terms of the overall burden of coronary lesions (Gensini score), and in terms of critical lesions (SYNTAX score). However, despite the similarity in coronary atherosclerosis, the present follow-up data show that women with earlier menopause had significantly worse 1-year outcome as compared with those with age at menopause above median.

The higher cardiovascular risk associated with early menopause, particularly in terms of cardiovascular mortality, has been shown in a longitudinal study of 12,115 postmenopausal women living in Utrecht, Netherlands, aged 50-65 years at enrolment in a breast cancer screening project [1]. In that study, with each year's delay in the menopause the cardiovascular mortality risk decreased by $2 \%$. That finding was confirmed by subsequent metanalyses of longitudinal studies of women without overt heart disease at baseline [2-5]. A recent report of the U.S. National Health and Nutrition Examination Survey also showed that a 1-year increase in the reproductive duration was associated 
Table 1

Baseline characteristics stratified according to menopausal age.

\begin{tabular}{|c|c|c|c|c|}
\hline Variable & $\begin{array}{l}\text { All patients } \\
\mathrm{n}=373\end{array}$ & $\begin{array}{l}\text { Menopausal age } \leq 50 \\
n=203\end{array}$ & $\begin{array}{l}\text { Menopausal age }>50 \\
\mathrm{n}=170\end{array}$ & $\mathrm{p}$ Value \\
\hline Age $(y)^{\mathrm{a}}$ & $73(65-82)$ & $73(65-83)$ & $74(65-80)$ & 0.79 \\
\hline Age at menopause (years) ${ }^{a}$ & $50(47-53)$ & $47(45-50)$ & $53(52-55)$ & $<0.001$ \\
\hline Fertility life span (years) ${ }^{a}$ & $38(34-40)$ & $34(31-37)$ & $41(39-42)$ & $<0.001$ \\
\hline Age from menopause to ACS (years) ${ }^{a}$ & $23(15-32)$ & $27(19-37)$ & $19(12-27)$ & $<0.001$ \\
\hline Body mass index $\left(\mathrm{Kg} / \mathrm{m}^{2}\right)^{\mathrm{a}}$ & $25.8(23.0-29.3)$ & $25.9(22.9-29.4)$ & $25.7(23.1-29.3)$ & 0.76 \\
\hline Hemoglobin $(\mathrm{gr} / \mathrm{dL})^{\mathrm{a}}$ & $12.8(11.6-14.0)$ & $12.7(11.6-14.0)$ & $12.8(11.6-13.8)$ & 0.62 \\
\hline Creatinine $(\mathrm{mg} / \mathrm{dL})^{\mathrm{a}}$ & $0.81(0.7-1.06)$ & $0.84(0.7-1.08)$ & $0.80(0.7-1.05)$ & 0.36 \\
\hline Creatinine clearance $(\mathrm{mL} / \mathrm{min})^{\mathrm{a}}$ & $72.6(53.6-88.4)$ & $70.7(52.5-88.4)$ & $74.5(54.5-88.2)$ & 0.39 \\
\hline Left ventricle ejection fraction ${ }^{a}$ & $50(40-55)$ & $50(40-55)$ & $50(40-55)$ & 0.58 \\
\hline Hypertension & $295(79.1)$ & $164(80.8)$ & $131(77.1)$ & 0.24 \\
\hline Hypercholesterolemia & $215(57.6)$ & $115(56.6)$ & $100(58.8)$ & 0.41 \\
\hline Smoking habit & $118(31.6)$ & $64(31.5)$ & $54(31.8)$ & 0.43 \\
\hline Family history of CAD & $73(19.6)$ & $43(21.2)$ & $30(17.6)$ & 0.28 \\
\hline Diabetes mellitus & $104(27.9)$ & $61(30.0)$ & $43(25.3)$ & 0.24 \\
\hline Chronic kidney disease & $36(9.6)$ & $26(12.8)$ & $10(5.9)$ & 0.03 \\
\hline COPD & $22(5.9)$ & $12(5.9)$ & $10(5.9)$ & 0.43 \\
\hline Prior stroke or TIA & $31(8.3)$ & $19(9.4)$ & $12(7.1)$ & 0.30 \\
\hline Peripheral artery disease & $46(12.3)$ & $26(12.8)$ & $20(11.8)$ & 0.41 \\
\hline Malignancies & $32(8.6)$ & $16(7.9)$ & $16(9.4)$ & 0.38 \\
\hline Prior MI & $52(13.9)$ & $30(14.8)$ & $22(12.9)$ & 0.37 \\
\hline Prior angina & $59(15.8)$ & $38(18.7)$ & $21(12.3)$ & 0.10 \\
\hline \multicolumn{5}{|l|}{ Prior revascularization } \\
\hline Prior PCI & $52(13.9)$ & $29(14.3)$ & $23(13.5)$ & 0.42 \\
\hline Prior CABG & $27(7.2)$ & $13(6.4)$ & $14(8.2)$ & 0.35 \\
\hline \multicolumn{5}{|l|}{ Diagnosis } \\
\hline STEMI & $189(50.7)$ & $104(51.2)$ & $85(50.0)$ & 0.81 \\
\hline NSTEMI & $184(49.3)$ & $99(48.8)$ & $85(50.0)$ & \\
\hline \multicolumn{5}{|l|}{ Killip class presentation } \\
\hline I & $304(81.5)$ & $164(80.8)$ & $140(82.3)$ & 0.89 \\
\hline II & $36(9.6)$ & $19(9.4)$ & $17(10.0)$ & 0.96 \\
\hline III & $24(6.4)$ & $14(6.9)$ & $10(5.9)$ & 0.91 \\
\hline IV & $5(1.3)$ & $4(2.0)$ & $1(0.6)$ & 0.51 \\
\hline \multicolumn{5}{|c|}{ Cardiovascular medications taken during the last 30 days prior to hospital admission } \\
\hline Beta-blockers & $143(38.3)$ & $76(37.4)$ & $67(39.4)$ & 0.19 \\
\hline Acetil salicilic acid & $131(51.1)$ & $71(34.9)$ & $60(35.3)$ & 0.27 \\
\hline $\mathrm{P}_{2} \mathrm{Y}_{12}$ inhibitors & $40(10.7)$ & $24(11.8)$ & $16(9.4)$ & 0.29 \\
\hline ACE-inhibitors & $113(30.1)$ & $75(36.9)$ & $38(22.3)$ & 0.01 \\
\hline Angiotensin receptor antagonists & $40(10.7)$ & $21(10.3)$ & $19(11.2)$ & 0.49 \\
\hline Statins & $130(34.8)$ & $68(33.5)$ & $62(36.5)$ & 0.16 \\
\hline Diuretics & $126(33.8)$ & $76(37.4)$ & $50(29.4)$ & 0.16 \\
\hline Calcium channel blockers & $64(17.1)$ & $33(16.3)$ & $31(18.2)$ & 0.23 \\
\hline Oral anticoagulants & $26(7.0)$ & $14(6.9)$ & $12(7.1)$ & 0.32 \\
\hline Nitrates & $33(8.8)$ & $20(9.8)$ & $13(7.6)$ & 0.29 \\
\hline Anti-arrhythmics & $15(4.0)$ & $9(4.4)$ & $6(3.5)$ & 0.32 \\
\hline
\end{tabular}

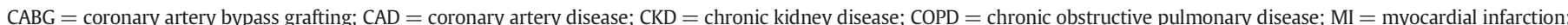
NSTEMI = non-ST-elevation myocardial infarction; $\mathrm{PCI}=$ percutaneous coronary intervention; STEMI = ST-elevation myocardial infarction. TIA = transient ischemic attack.

a Expressed as median and interquartile range. Categorical data are expressed as numbers and percentage.

with a $3 \%$ reduction in the risk of events, particularly stroke and angina [19].

The pathophysiological mechanism of this association remains disputed so far. Since modifiable risk factors have been shown to account for $90 \%$ of MIs in both sexes [20], the relation of menopausal age with the subsequent evolution of these risk factors has been investigated. In an analysis derived from the EPIC-INTERACT study, women with an early age at menopause onset (defined as $<42$ years) were at higher risk of developing type- 2 diabetes [10]. However, a study in a large population-based cohort in the Netherlands showed only a modest impact of menopause on risk factors [21]. An opposite view that a worse heart disease profile determines an earlier menopause was suggested by data coming from Framingham Heart study [11]. In that analysis, 695 women who were premenopausal at the study entry had their cardiovascular risk factors measured and were followed until the time of their natural menopause, showing that every $1 \%$ increase in premenopausal Framingham risk score was associated with a decrease in menopausal age of 1.8 years.

We studied the coronary angiograms of postmenopausal women with acute MI, of which $85 \%$ were at their first episode [12], and correlated this data with menopausal age, and prospectively with one-year outcome. We found no material differences in baseline characteristics, except for the presence of chronic kidney dysfunction, a powerful prognostic indicator and marker of macro- and microvascular damage [22], which was more frequent among women with early menopause. Whereas age at menopause was not associated with the extent of coronary disease at angiography [12], women with earlier menopause showed significantly worse outcome. All the ischemic components of the composite outcome were more frequent among women with earlier menopause, except rehospitalizations. Importantly, menopausal age showed an association with adverse cardiovascular outcome independent of other powerful predictors, such as age, LVEF and SYNTAX score. These findings are consistent with the results of longitudinal studies in women without known cardiovascular disease at baseline, and showing an increased risk of subsequent cardiovascular mortality among women with early onset menopause [1-6]. Early menopause has also been found associated with an increased risk of developing heart failure later in life [23-25]. In the present study, women with early menopause were taking significantly more ACE-inhibitors prior to admission, which may be an indirect index of prior heart failure symptoms, although baseline LVEF was the same in both groups. Altogether, these data consolidate the concept that early menopause is associated with worse cardiovascular 
Table 2

Angiographic and interventional data stratified according to classes at menopause.

\begin{tabular}{|c|c|c|c|c|}
\hline Variable & $\begin{array}{l}\text { All patients } \\
\mathrm{n}=373\end{array}$ & $\begin{array}{l}\text { Menopausal age } \leq 50 \\
n=203\end{array}$ & $\begin{array}{l}\text { Menopausal age }>50 \\
\mathrm{n}=170\end{array}$ & $\mathrm{p}$ Value \\
\hline Radial access site & $298(79.9)$ & $160(78.8)$ & $138(81.2)$ & 0.77 \\
\hline Gensini score ${ }^{a}$ & $46(24-68)$ & $47(27-67)$ & $44(22-68)$ & 0.50 \\
\hline Gensini score $^{\mathrm{b}}$ & $49.7 \pm 31.5$ & $50.2 \pm 29.9$ & $49.2(33.3)$ & 0.78 \\
\hline SYNTAX score ${ }^{a}$ & $12(6-21)$ & $12(7-22)$ & $12(5-21)$ & 0.89 \\
\hline SYNTAX score $^{\mathrm{b}}$ & $14.9 \pm 12.4$ & $14.9 \pm 11.9$ & $15.0 \pm 12.8$ & 0.94 \\
\hline \multicolumn{5}{|l|}{ Coronary revascularization } \\
\hline $\mathrm{PCI}$ & $267(71.6)$ & $153(75.4)$ & $114(67.1)$ & 0.24 \\
\hline CABG & $13(3.5)$ & $5(2.5)$ & $8(4.7)$ & \\
\hline Total number of lesions treated ${ }^{\mathrm{a}}$ & $1(1-1)$ & $1(1-1)$ & $1(1-1)$ & 0.75 \\
\hline Total number of stents implanted ${ }^{a}$ & $1(0-1)$ & $1(0-1)$ & $1(0-1)$ & 0.27 \\
\hline \multicolumn{5}{|l|}{ Drugs at discharge } \\
\hline Beta-blockers & $304(81.5)$ & $163(80.3)$ & $141(82.9)$ & 0.47 \\
\hline Acetil salicilic acid & $348(93.3)$ & $189(93.1)$ & $159(93.5)$ & 0.42 \\
\hline $\mathrm{P}_{2} \mathrm{Y}_{12}$ inhibitors & $309(82.8)$ & $171(84.2)$ & $138(81.2)$ & 0.43 \\
\hline Clopidogrel & $162(43.4)$ & $83(40.9)$ & $79(46.5)$ & \\
\hline Prasugrel & $70(18.8)$ & $44(21.7)$ & $26(15.3)$ & \\
\hline Ticagrelor & $77(20.6)$ & $44(21.7)$ & $33(19.4)$ & \\
\hline ACE-inhibitors & $248(66.5)$ & $141(69.5)$ & $107(62.9)$ & 0.14 \\
\hline Angiotensin receptor antagonists & $85(22.8)$ & $43(21.2)$ & $42(24.7)$ & 0.15 \\
\hline Statins & $336(90.1)$ & $183(90.1)$ & $153(90)$ & 0.40 \\
\hline Diuretics & $169(45.3)$ & $89(43.8)$ & $80(47.1)$ & 0.44 \\
\hline Calcium channel blockers & $74(19.8)$ & $34(16.7)$ & $40(23.5)$ & 0.15 \\
\hline Oral anticoagulants & $39(10.5)$ & $19(9.4)$ & $20(11.8)$ & 0.39 \\
\hline Oral anti-diabetics & $53(14.2)$ & $33(16.3)$ & $20(11.8)$ & 0.21 \\
\hline Insulin & $41(11.0)$ & $21(10.2)$ & $20(11.8)$ & 0.46 \\
\hline Nitrates & $48(12.9)$ & $25(12.3)$ & $23(13.5)$ & 0.48 \\
\hline Anti-arrhythmics & $23(6.2)$ & $13(6.4)$ & $10(5.9)$ & 0.48 \\
\hline Proton pump inhibitors & $288(77.2)$ & $165(81.3)$ & $123(72.3)$ & 0.02 \\
\hline
\end{tabular}

$\mathrm{CABG}=$ coronary artery bypass grafting; $\mathrm{PCI}=$ percutaneous coronary intervention.

Categorical data are expressed as numbers and percentage.

a Expressed as median and interquartile range.

b Expressed as mean and standard deviation.

outcome, most likely of multifactorial origin and needing more focused investigation.

According to the Ladies ACS study [12], a greater coronary atherosclerotic burden may not play a major causative role with respect to the risk of developing an ACS among women with early menopause. However, coronary angiography is not a sensitive method for investigating coronary atherosclerosis; it stands midway between the calcium score, suitable for screening studies, and more sophisticated imaging techniques, such as those based on intravascular ultrasounds and optical computerized tomography (OCT). The more sophisticated study so far [26], using OCT to characterize plaque morphology and composition among (mostly post-menopausal) women and age-matched men with ST-elevation MI, did not find any quantitative or qualitative difference between sexes, though women had significantly smaller coronary arteries, a feature that might expose them to a higher impact of vasomotor stimuli and more frequent anginal symptoms. However, even these sophisticated imaging methods are not suitable for investigating the vasomotor and microvascular components of coronary circulation, which may play a key role in the causation and outcome of ACS $[27,28]$. Whether the dynamic component of coronary circulation may differ according to menopausal age, particularly in women with a higher atherosclerotic burden may be matter for further investigation.

\subsection{Limitations}

The Ladies ACS study enrolled only patients aged $\geq 55$ years. Therefore, patients with very young menopausal age and with an ACS before 55 years were not included. The study was an investigation on angiographically assessed coronary atherosclerosis, including only women undergoing coronary angiography because of an ACS with ischemic ECG changes and elevated troponin levels. Therefore, our conclusion is limited to this study population which, however, represents the large

Table 3

In-hospital and follow-up events according to age at menopause (median age 51 years).

\begin{tabular}{|c|c|c|c|c|c|c|}
\hline Variable & $\begin{array}{l}\text { All patients } \\
\mathrm{n}=373\end{array}$ & $\begin{array}{l}\text { Menopausal age } \leq 50 \\
\mathrm{n}=203\end{array}$ & $\begin{array}{l}\text { Menopausal age }>50 \\
\mathrm{n}=170\end{array}$ & $\mathrm{p}$ Value & $\begin{array}{l}\text { Adjusted odds } \\
\text { ratio ( } 95 \% \text { C.I.) }\end{array}$ & p Value ${ }^{a}$ \\
\hline $\begin{array}{l}\text { Composite 1-year outcome } \\
\text { (death, myocardial infarction, and stroke) }\end{array}$ & $42(11.3)$ & $31(15.3)$ & $11(6.5)$ & 0.007 & $0.28(0.12-0.67)^{\mathrm{b}}$ & 0.004 \\
\hline In-hospital death & $8(2.1)$ & $6(3.0)$ & $2(1.2)$ & 0.24 & $0.36(0.06-1.96)$ & 0.24 \\
\hline Follow-up death & $13(3.5)$ & $9(4.4)$ & $4(2.3)$ & 0.27 & $0.71(0.19-2.71)$ & 0.63 \\
\hline In-hospital \& follow-up death & $21(5.6)$ & $15(7.4)$ & $6(3.5)$ & 0.11 & $0.50(0.17-1.50)$ & 0.22 \\
\hline In-hospital \& follow-up cardiovascular death & $6(1.6)$ & $5(2.4)$ & $1(0.6)$ & 0.25 & $0.32(0.08-1.29)$ & 0.11 \\
\hline Recurrent myocardial infarction & $18(4.8)$ & $13(6.4)$ & $5(2.9)$ & 0.07 & $0.24(0.06-0.95)$ & 0.04 \\
\hline Stroke & $3(0.8)$ & $3(1.5)$ & 0 & 0.07 & - & - \\
\hline Rehospitalization for cardiovascular causes & $42(11.3)$ & $23(11.3)$ & $19(11.2)$ & 0.27 & $0.97(0.39-2.37)$ & 0.95 \\
\hline Overall outcome events & $77(20.6)$ & $50(24.6)$ & $27(15.9)$ & 0.04 & $0.54(0.31-0.94)^{\mathrm{b}}$ & 0.03 \\
\hline
\end{tabular}

Categorical data are expressed as numbers and percentage.

a Adjusted for age, ejection fraction and SYNTAX score.

b The reference category is age at menopause $<51$ years. 
majority of ACS patients in Europe. The most severe cases (such as those with out of hospital cardiac arrest), and also patients with unstable angina and no troponin elevations (such as many of those with variant angina or pure microvascular angina) have not been included in the Ladies ACS population. However, our results are in the same direction of longitudinal studies with no overt cardiac disease at baseline [1-6], and reinforce their conclusion of an increase cardiovascular risk associated with younger menopausal age.

We had no information on the date of the follow-up events. Considering the short follow-up, the implications of this are however limited.

The limits of menopause reporting using questionnaires several years after actual menopause have been quantified within one year of variation in recall studies [29-31], and appear acceptable for the purposes of the present analysis.

\section{Conclusions}

Women reporting menopausal age below median have significantly worse outcomes within one year after an ACS, as compared with women with later menopause. This worse outcome is not explained by differences in cardiovascular risk factors, prior cardiovascular events, age at index ACS, severity of coronary angiographic findings and ejection fraction. The pathophysiological reasons behind these findings should be further investigated using functional testing of the endothelium and microvasculature beyond the limits of current imaging methods [28].

\section{Disclosures}

None of the authors report any conflict of interest with the specific subject of the study.

\section{References}

[1] Y.T. van der Schouw, Y. van der Graaf, E.W. Steyerberg, M.J.C. Eijkemans, J.D. Banga, Age at menopause as a risk factor for cardiovascular mortality, Lancet 347 (1996) 714-718.

[2] F. Atsma, M.L.E.L. Bartelink, D.E. Grobbee, Y.T. van der Schouw, Postmenopausal status and early menopause as independent risk factors for cardiovascular disease: a meta-analysis, Menopause 13 (2006) 265-279.

[3] J.E. Roeters van Lennep, K.Y. Heida, M.L. Bots, A. Hoek, collaborators of the Dutch Multidisciplinary Guideline Development Group on Cardiovascular Risk Management after Reproductive Disorders, Cardiovascular disease risk in women with premature ovarian insufficiency: a systematic review and meta-analysis, Eur. J. Prev. Cardiol. 23 (2016) 178-186.

[4] X.Y. Tao, A.Z. Zuo, J.Q. Wang, F.B. Tao, Effect of primary ovarian insufficiency and early natural menopause on mortality: a meta-analysis, Climacteric 19 (2016) 27-36.

[5] T. Muka, C. Oliver-Williams, S. Kunutsor, J.S. Laven, B.C. Fauser, R. Chowdhury, M. Kavousi, O.H. Franco, Association of age at onset of menopause and time since onset of menopause with cardiovascular outcomes, intermediate vascular traits, and all-cause mortality: a systematic review and meta-analysis, JAMA Cardiol. 1 (2016) 767-776.

[6] L. Yang, L. Lin, C. Kartsonaki, Y. Guo, Y. Chen, Z. Bian, K. Xie, D. Jin, L. Li, L. Lv, Z. Chen, on behalf of the China Kadoorie Biobank Study Collaborative Group, Menopause characteristics, total reproductive years, and risk of cardiovascular disease among Chinese women, Circ. Cardiovasc. Qual. Outcomes 10 (2017), e004235.

[7] L. Stolk, J.R. Perry, D.I. Chasman, C. He, M. Mangino, P. Sulem, M. Barbalic, L. Broer, E.M. Byrne, F. Ernst, T. Esko, N. Franceschini, D.F. Gudbjartsson, J.J. Hottenga, P. Kraft, P.F. McArdle, E. Porcu, S.Y. Shin, A.V. Smith, S. van Wingerden, G. Zhai, W.V. Zhuang, E. Albrecht, B.Z. Alizadeh, T. Aspelund, S. Bandinelli, L.B. Lauc, J.S. Beckmann, M. Boban, E. Boerwinkle, FJ. Broekmans, A. Burri, H. Campbell, S.J. Chanock, C. Chen, M.C. Cornelis, T. Corre, A.D. Coviello, P. d'Adamo, G. Davies, U. de Faire, E.J. de Geus, I.J. Deary, G.V. Dedoussis, P. Deloukas, S. Ebrahim, G. Eiriksdottir, V. Emilsson, J.G. Eriksson, B.C. Fauser, L. Ferreli, L. Ferrucci, K. Fischer, A.R. Folsom, M.E. Garcia, P. Gasparini, C. Gieger, N. Glazer, D.E. Grobbee, P. Hall, T. Haller, S.E. Hankinson, M. Hass, C. Hayward, A.C. Heath, A. Hofman, E. Ingelsson, A.C. Janssens, A.D. Johnson, D. Karasik, S.L. Kardia, J. Keyzer, D.P. Kiel, I. Kolcic, Z. Kutalik, J. Lahti, S. Lai, T. Laisk, J.S. Laven, D.A. Lawlor, J. Liu, L.M. Lopez, Y.V. Louwers, P.K. Magnusson, M. Marongiu, N.G. Martin, I.M. Klaric, C. Masciullo, B. McKnight, S.E. Medland, D. Melzer, V. Mooser, P. Navarro, A.B. Newman, D.R. Nyholt, N.C. Onland-Moret, A. Palotie, G. Paré, A.N. Parker, N.L. Pedersen, P.H. Peeters, G. Pistis, A.S. Plump, O. Polasek, V.J. Pop, B.M. Psaty, K. Räikkönen, E. Rehnberg, J.I. Rotter, I. Rudan, C. Sala, A. Salumets, A. Scuteri, A. Singleton, J.A. Smith, H. Snieder, N. Soranzo, S.N. Stacey, J.M. Starr, M.G. Stathopoulou, K. Stirrups, R.P. Stolk, U. Styrkarsdottir, Y.V. Sun, A.
Tenesa, B. Thorand, D. Toniolo, L. Tryggvadottir, K. Tsui, S. Ulivi, R.M. van Dam, Y.T van der Schouw, C.H. van Gils, P. van Nierop, J.M. Vink, P.M. Visscher, M. Voorhuis, G. Waeber, H. Wallaschofski, H.E. Wichmann, E. Widen, C.J. Wijnands-van Gent, G. Willemsen, J.F. Wilson, B.H. Wolffenbuttel, A.F. Wright, L.M. Yerges-Armstrong, T. Zemunik, L. Zgaga, M.C. Zillikens, M. Zygmunt, LifeLines Cohort Study, A.M. Arnold, D.I. Boomsma, J.E. Buring, L. Crisponi, E.W. Demerath, V. Gudnason, T.B. Harris, F.B. Hu, D.J. Hunter, L.J. Launer, A. Metspalu, G.W. Montgomery, B.A. Oostra, P.M. Ridker, S. Sanna, D. Schlessinger, T.D. Spector, K. Stefansson, E.A. Streeten, U. Thorsteinsdottir, M. Uda, A.G. Uitterlinden, C.M. van Duijn, H. Völzke, A. Murray, J.M. Murabito, J.A. Visser, K.L. Lunetta, Life Lines Cohort Study, Meta-analyses identify 13 loci associated with age at menopause and highlight DNA repair and immune pathways, Nat. Genet. 44 (2012) 260-268.

[8] M.E. Mendelsohn, R.H. Karas, The protective effects of estrogen on the cardiovascular system, N. Engl. J. Med. 340 (1999) 1801-1811.

[9] J.O.A. Manson, T.K. Woodruff, Reproductive health as a marker of subsequent cardiovascular disease. The role of estrogen, JAMA Cardiol. 1 (2016) 776-777.

[10] J.S. Brand, Y.T. Van Der Schouw, N.C. Onland-Moret, S.J. Sharp, K.K. Ong, K.T. Khaw, E. Ardanaz, P. Amiano, H. Boeing, M.D. Chirlaque, F. Clavel-Chapelon, F.L. Crowe, B. de Lauzon-Guillain, E.J. Duell, G. Fagherazzi, P.W. Franks, S. Grioni, L.C. Groop, R. Kaaks, T.J. Key, P.M. Nilsson, K. Overvad, D. Palli, S. Panico, J.R. Quirós, O. Rolandsson, C. Sacerdote, M.J. Sánchez, N. Slimani, B. Teucher, A. Tjonneland, R. Tumino, D.L. van der A, E.J. Feskens, C. Langenberg, N.G. Forouhi, E. Riboli, N.J. Wareham, InterAct Consortium, Age at menopause, reproductive life span, and type 2 diabetes risk, Diabetes Care 36 (2013) 1012-1019.

[11] H.S. Koh, K.M. van Asselt, Y.T. van der Schouw, I. van der Tweel, P.H. Peeters, P.W Wilson, P.L. Pearson, D.E. Grobbee, Heart disease risk determines menopausal age rather than the reverse, J. Am. Coll. Cardiol. 47 (2006) 1976-1983.

[12] S. Savonitto, D. Colombo, N. Franco, L. Misuraca, L. Lenatti, I.J. Romano, N. Morici, E. Lo Jacono, C. Leuzzi, E. Corrada, T.C. Aranzulla, G. Bellia, E. Romagnoli, A. Cagnacci, G. Biondi Zoccai, F. Prati, Age at menopause and extent of coronary artery disease among post-menopausal women with acute coronary syndromes: a prospective age and sex-matched study. The LADIES ACS study, Am. J. Med. 129 (2016) 1205-1212.

[13] K. Thygesen, J.S. Alpert, A.S. Jaffe, M.L. Simoons, B.R. Chaitman, H.D. White, Joint ESC/ ACCF/AHA/WHF Task Force for Universal Definition of Myocardial Infarction, Writing Group on the Joint ESC/ACCF/AHA/WHF Task Force for the Universal Definition of Myocardial Infarction, ESC Committee for Practice Guidelines (CPG), Third universal definition of myocardial infarction, Eur. Heart J. 33 (2012) 2551-2567.

[14] G.G. Gensini, A more meaningful scoring system for determining the severity of coronary heart disease, Am. J. Cardiol. 51 (1983) 606.

[15] I.J. Neeland, R.S. Patel, P. Eshtehardi, S. Dhawan, M.C. McDaniel, S.T. Rab, V. Vaccarino, A.M. Zafari, H. Samady, A.A. Quyyumi, Coronary angiographic scoring systems: an evaluation of their equivalence and validity, Am. Heart J. 164 (2012) 547-552.e1.

[16] G. Sianos, M.A. Morel, A.P. Kappetein, M.C. Morice, A. Colombo, K. Dawkins, M. van den Brand, N. Van Dyck, M.E. Russell, F.W. Mohr, P.W. Serruys, The SYNTAX score: an angiographic tool grading the complexity of coronary artery disease, Eurolntervention 1 (2005) 219-227.

[17] S.H. Ley, Y. Li, D.K. Tobias, M.D.J.A.E. Manson, B. Rosner, F.B. Hu, K.M. Rexrode, Duration of reproductive life span, age at menarche, and age at menopause are associated with risk of cardiovascular disease in women, J. Am. Heart Assoc. 6 (2017), e006713.

[18] S. Palacios, V.W. Henderson, N. Siseles, D. Tan, P. Villaseca, Age of menopause and impact of climacteric symptoms by geographical region, Climacteric 13 (2010) 419-428.

[19] H. Mansoor, I.Y. Elgendy, R. Segal, A. Hartzema, Duration of reproductive years and the risk of cardiovascular and cerebrovascular events in older women: insights from the National Health and Nutrition Examination Survey, J. Women's Health (Larchmt) 26 (2017) 1047-1052.

[20] S. Yusuf, S. Hawken, S. Ounpuu, T. Dans, A. Avezum, F. Lanas, M. McQueen, A. Budaj, P. Pais, J. Varigos, L. Lisheng, INTERHEART Study Investigators, Effect of potentially modifiable risk factors associated with myocardial infarction in 52 countries (the INTERHEART study): case-control study, Lancet 364 (2004) 937-952.

[21] A.C. de Kat, V. Dam, N.C. Onland-Moret, M.J.C. Eijkemans, F.J.M. Broekmans, Y.T. van der Schouw, Unraveling the associations of age and menopause with cardiovascular risk factors in a large population-based study, BMC Med. 15 (2017) 2.

[22] V.L. Murthy, M. Naya, C.R. Foster, J. Hainer, M. Gaber, S. Dorbala, D.M. Charytan, R. Blankstein, M.F. Di Carli, Coronary vascular dysfunction and prognosis in patients with chronic kidney disease, JACC Cardiovasc. Imaging 5 (2012) 1025-1034.

[23] I.A. Ebong, K.E. Watson, D.C. Goff Jr., D.A. Bluemke, P. Srikanthan, T. Horwich, A.G. Bertoni, Age at menopause and incident heart failure: the multi-ethnic study of atherosclerosis, Menopause 21 (2014) 585-591.

[24] I. Rahman, A. Akesson, A. Wolk, Relationship between age at natural menopause and risk of heart failure, Menopause 22 (2015) 12-16.

[25] D. Appiah, P.J. Schreiner, E.W. Demerath, L.R. Loehr, P.P. Chang, A.R. Folsom, Association of age at menopause with incident heart failure: a prospective cohort study and meta-analysis, J. Am. Heart Assoc. 5 (2016), e003769.

[26] G. Guagliumi, D. Capodanno, F. Saia, G. Musumeci, G. Tarantini, R. Garbo, G. Tumminello, V. Sirbu, M. Coccato, M. Fineschi, C. Trani, M. De Benedictis, U. Limbruno, L. De Luca, G. Niccoli, H. Bezerra, E. Ladich, M. Costa, G. Biondi Zoccai, R. Virmani, OCTAVIA Trial Investigators, Mechanisms of atherothrombosis and vascular response to primary percutaneus coronary intervention in women versus men with acute myocardial infarction: results of the OCTAVIA study, JACC Cardiovasc. Interv. 7 (2014) 958-968. 
[27] V.L. Murthy, M. Naya, V.R. Taqueti, C.R. Foster, M. Gaber, J. Hainer, S. Dorbala, R. Blankstein, O. Rimoldi, P.G. Camici, M.F. Di Carli, Effects of sex on coronary microvascular dysfunction and cardiac outcomes, Circulation 129 (2014) 2518-2527.

[28] F. Crea, P. Libby, Acute coronary syndromes: the way forward from mechanisms to precision treatment, Circulation 136 (2017) 1155-1166.

[29] G.A. Colditz, M.J. Stampfer, W.C. Willett, W.B. Stason, B. Rosner, C.H. Hennekens, F.E. Speizer, Reproducibility and validity of self-reported menopausal status in a prospective cohort study, Am. J. Epidemiol. 126 (1987) 319-325.
[30] R. Hahn, E. Eaker, H. Rolka, Reliability of reported age at menopause, Am. J. Epidemiol. 146 (1997) 771-775.

[31] K. Rödström, C. Bengtsson, L. Lissner, C. Björkelund, Reproducibility of self-reported menopause age at the 24-year follow-up of a population study of women in Goteborg, Sweden, Menopause 12 (2005) 275-280. 